\title{
MÚSICA E MÍDIAS: CONTRIBUIÇÕES DAS TESES E DISSERTAÇÕES BRASILEIRAS PARA A FORMAÇÃO DE PROFESSORES
}

\author{
MUSIC AND MEDIA: CONTRIBUTION OF BRAZILIAN THESES \\ AND DISSERTATIONS TO TEACHER EDUCATION
}

\section{MÚSICA Y MEDIOS: CONTRIBUCIONES DE TESIS Y DISERTACIONES BRASILEÑAS A LA FORMACIÓN DE PROFESORES}

\begin{abstract}
Resumo: $O$ artigo analisa um mapeamento das 16 teses e 22 dissertações sobre música e mídias realizadas nos cursos brasileiros de Pós-Graduação em Educação e em Música (2000-2018), com o objetivo de sistematizar suas contribuições para a formação de professores. A análise documental, inspirada em André (2009), concentrou-se em 19 dessas pesquisas, e, a partir de referências teóricas da educação musical (Bellochio), e da mídia-educação (Buckingham; Richards), mostrou que os temas mais estudados são os usos e influências das mídias na relação dos jovens com a música; que os professores precisam estar atentos aos novos desdobramentos culturais; e que os saberes musicais dos estudantes deveriam ser compartilhados e discutidos na escola. Conclui-se apontando a necessidade de a música e as mídias estarem presentes na formação de professores, aproximando a escola das vivências dos jovens e favorecendo novas formas de aprendizagem musical e de reflexão crítica e criadora para professores e estudantes.
\end{abstract}

Palavras-chave: música, mídias, mídia-educação, formação de professores.

Abstract: The article analyzes a mapping of the $22 \mathrm{MA}$ and $16 \mathrm{PhD}$ dissertations on music and media carried out in Brazilian Graduate Programs in Education and in Music (2000-2018), aiming at contributing to teacher training. Based upon theoretical references in music education (Bellochio) and media-education (Buckingham; Richards), the documental analysis (André) focused on 19 of those works and found that the themes most frequently studied are the influence of media on the role of music in the lives of young people; the need for teachers to be aware of new cultural developments; and the importance of students' musical knowledge to be shared and discussed at

\footnotetext{
${ }^{1}$ Universidade Federal de Santa Catarina, Florianópolis, Santa Catarina, Brasil.

${ }^{2}$ Universidade Federal de Santa Catarina, Florianópolis, Santa Catarina, Brasil.
} 
school. The conclusion points to the need for music and media to be present in teacher training, bringing the school closer to young people's experiences, and favoring new forms of musical learning, as well as critical and creative cultural approaches for teachers and students.

Keywords: music, media, media-education, teacher training.

Resumen: El artículo analiza un mapa de 16 tesis y 22 disertaciones sobre música y medios de comunicación realizadas en los Cursos de Postgrado en Educación y Música del Brasil (2000-2018), con el objetivo de sistematizar sus contribuciones a la formación de profesores. El análisis documental, inspirado por André (2009), se centró en 19 de estas investigaciones, las cuales se basan en referencias teóricas de la educación musical (Bellochio) y en la educación sobre los medios de comunicación (Buckingham; Richards). Los temas más estudiados son: los usos e influencias de los medios de comunicación en la relación de los jóvenes con la música; la atención de los profesores en los nuevos desarrollos culturales y la necesidad de compartir y discutir los conocimientos musicales de los estudiantes en la escuela. Como conclusión se señala la necesidad de que la música y los medios de comunicación estén presentes en la formación de los profesores, acercando la escuela a las experiencias de los jóvenes y favoreciendo nuevas formas de aprendizaje musical y de reflexión crítica y creativa para profesores y alumnos.

Palabras clave: música, medios, educación en medios, formación del profesorado.

\section{INTRODUÇÃO}

Na cultura digital contemporânea, a presença da música e do consumo musical no cotidiano das crianças e dos jovens modificou-se radicalmente em relação ao final do século passado, envolvendo toda uma mistura de ritmos, estéticas e estilos de vida (SODRÉ, 2012). Nesse cenário cultural híbrido, a ubiquidade das mídias marca modos novos e complexos de interação social, percepção e linguagem também em relação às artes e especificamente à música. Novas sensibilidades e escrituras desenham-se no horizonte, bem como novos deslocamentos entre saber e informação, razão e imaginação, arte e ciência. Desse modo, a produção contemporânea de arte e mídia precisa ser incorporada à educação escolar para que esta, além de mais motivadora, se torne também mais relevante (KELLNER; SHARE, 2008).

Considerando tal contexto, temos como pressupostos que a música e as mídias estão presentes no cotidiano de crianças e jovens e que os espaços de formação de professores, mais especificamente os cursos de Pedagogia, são lugares potencialmente privilegiados para a formação e a reflexão sobre tais temas. Apesar disso, são raras as referências disponíveis aos professores e estudantes de Pedagogia em que haja um diálogo mais amplo e sistemático entre as pesquisas feitas no campo da música e no da educação. Deste modo, o artigo tem como núcleo empírico um 
mapeamento de pesquisas brasileiras de mestrado e doutorado realizadas nas últimas duas décadas, que articulam música e mídia no contexto educacional. Para a análise do material, trazemos referências teóricas tanto da educação musical quanto da mídia-educação, buscando assim contribuir para o esforço de aproximar a escola das vivências midiático-musicais que são tão centrais na vida dos estudantes.

\section{SOBRE A MÚSICA NA FORMAÇÃO DAS CRIANÇAS E DOS JOVENS}

Sabe-se que a música, como toda forma de arte, tem uma imensa contribuição a dar para a formação integral das crianças e dos jovens. A "fecundação cruzada" entre as artes e outros campos de conhecimento, como por exemplo, entre a música e a matemática, é o grande catalisador das criações e descobertas humanas, também no campo da educação (ATALAY, 2007). Um importante estudo feito nos EUA (CATTERALL, 2012), acompanhando crianças e jovens de famílias de baixa renda ao longo de sua vida escolar, mostrou que aqueles que viveram mais experiências com as artes na escola - música, teatro, dança, artes visuais - tiveram um desenvolvimento humano mais pleno e harmonioso do que os que não tiveram tais experiências, e ao mesmo tempo se mostraram mais à vontade também em outras áreas de conhecimento. $E$ a aprendizagem especificamente musical na educação básica permite que os estudantes "desenvolvam compreensões críticas e as expressem em termos musicais; sejam capazes de fazer conexões sociais, culturais e históricas por meio da música; e estabeleçam relações criativas com outras disciplinas e com as tecnologias por meio da música" (NEW YORK CITY, 2015, p.11). A experiência musical do "ouvir" é especialmente importante na infância e adolescência, quando estamos mais abertos a conhecer novos estilos, do que a partir do início da idade adulta (PALHEIROS, 2006).

$\mathrm{Na}$ escola brasileira, desde o final do último século houve muitos movimentos para que a música fosse incluída nos currículos de forma eficaz. Esse movimento resultou na criação de Leis, tanto no campo do ensino da Arte como no da formação em Pedagogia.

Em relação à legislação para Arte na escola, a Lei de Diretrizes e Bases da Educação Nacional (LDB, 1996) estabelece que "o ensino da arte constituirá componente curricular obrigatório, nos diversos níveis da educação básica, de forma a promover o desenvolvimento cultural dos alunos" (BRASIL, 1996, artigo 26). Desta forma, a designação Educação Artística foi substituída pelo termo Arte, sugerindo o fim da prática polivalente. 
Em 2008, após um movimento articulado entre músicos, educadores musicais e representantes políticos do país (BELLOCHIO, WEBER e SOUZA, 2017), foi sancionada a Lei no 11.769/2008, que modificou o Art. 26 da LDB, o qual tentou assegurar um espaço para a música na escola através de um termo legal de validade nacional. Temos claro, entretanto, que determinações legais não geram automaticamente mudanças na organização e na prática escolar, embora a nova lei possa, sem dúvida, ser utilizada para respaldar ações promotoras de mudanças (PENNA, 2013). Essa visão de que a música deveria ser conteúdo obrigatório "possibilitou pensar com maior acuidade sobre as relações entre a formação e a atuação com música de professores de educação infantil e anos iniciais do ensino fundamental" (SCHWAN, BELLOCHIO, AHMAD, 2018, p. 116).

Mais recentemente, a LDB foi modificada pela Lei no 13.278 (BRASIL, 2016), onde consta que as artes visuais, a dança, a música e o teatro são as linguagens que constituirão o componente curricular do ensino de Arte. Com a atualização da LDB e considerando as orientações das diretrizes específicas, Figueiredo (2017) afirma que o pedagogo deveria ser capaz de atuar com estas quatro áreas das artes, o que implica a necessidade de formação nessas quatro áreas em sua graduação universitária.

Em relação à formação em Pedagogia, as Diretrizes Curriculares Nacionais para o Curso de Graduação em Pedagogia - Licenciatura (CNE/CP n.1, 2006) - orientam que o egresso deve estar apto a ensinar artes ${ }^{3}$, dentre as diversas áreas. Entretanto, muitas professoras de referência, ou seja, aquelas formadas em Pedagogia e que convivem a maior parte do tempo com as crianças na educação infantil ou nos anos iniciais da educação básica, acabam não trabalhando a música, por se sentirem inseguras para utilizá-la como recurso pedagógico (VALLIENGO, 2007); ou então, quando trazem a música para suas práticas, o fazem de modo apenas instrumental, como no uso de cantigas para ensinar outros conteúdos, sem valorizá-la de forma mais ampla, como uma área de conhecimento humano (BELLOCHIO, 2004; CORREA, 2008).

Mais recentemente, Bellochio, Weber e Souza (2017, p. 218) fizeram uma revisão das pesquisas que refletem sobre a educação musical em relação à unidocência, ou seja, em relação “às formas de trabalho docente do professor que atua na Educação Infantil e nos anos iniciais do Ensino Fundamental, como professor de referência" (BELLOCHIO; SOUZA, 2017, p. 23-24). As autoras concluem que são as vivências com a música durante sua formação acadêmica que fazem

\footnotetext{
${ }^{3}$ Art. 5o - O egresso do curso de Pedagogia deverá estar apto a: VI- ensinar Língua Portuguesa, Matemática, Ciências, História, Geografia, Artes, Educação Física, de forma interdisciplinar e adequada às diferentes fases do desenvolvimento humano (Resolução CNE/CP N. 1, de 15 de maio de 2006).
} 
com que os professores busquem promover atividades musicais com seus alunos. Fica clara, assim, a importância da música na formação de professores, particularmente na graduação em Pedagogia.

\section{SOBRE MÍDIAS E MÚSICA NA EDUCAÇÃO}

Desde os anos de 1930, vários pesquisadores usaram a teoria social crítica para analisar dimensões ideológicas e de controle social na indústria cultural e a partir de cada nova tecnologia de mídia que era popularizada. A partir da década de 1960, abordagens como a dos Estudos Culturais permitiram compreensões mais sofisticadas da recepção como construção ativa de significados. Em grande parte das propostas pedagógicas associadas a tais abordagens, a educação para a leitura crítica das mídias foi sempre apontada como aspecto importante, ainda que a partir dos anos 1990 a ênfase maior tenha passado a estar na produção de mídia por crianças e jovens, inclusive como espaço de apropriação crítica. Mudanças na cultura, a partir das facilidades técnicas de criação e compartilhamento promovidas pela chamada Web 2.0, exigiram uma retomada da atenção à formação crítica na mídia-educação.

Assim, em um texto que se tornou bastante influente, Jenkins et al (2009) defenderam vigorosamente o papel da mídia-educação na cultura participativa da internet, questionando a ideia corrente de que as crianças e os jovens, por serem tão fluentes nas novas mídias, aprenderiam sozinhos tudo o que precisavam saber sobre elas: "As crianças precisam de um espaço seguro onde possam desenvolver as habilidades necessárias para serem cidadãos e consumidores, aprendendo a identificar mensagens provenientes de grupos com seus próprios interesses e a separar fato de falsidade, à medida que experimentam novas formas de expressão criativa e participação comunitária"(JENKINS et al. 2009, p. 16). Mais recentemente, David Buckingham enfatizou que a dimensão crítica é hoje mais importante do que nunca na mídia-educação, diante do poder dos novos impérios digitais, como Google, Facebook, Apple e Amazon, que, embora "gostem de se apresentar como provedores neutros de serviços tecnológicos" (BUCKINGHAM, 2018, p.9), resistem a assumir responsabilidade pelos conteúdos que fornecem, mesmo em meio às ondas de discursos de ódio e fake-news.

Ainda na perspectiva da mídia-educação, mas com um olhar mais específico para a música, Chris Richards (1994, 1995), no contexto britânico, considera que o professor deve concentrar seus esforços para construir novas maneiras de falar sobre como e por que a música é importante. Afirma que o envolvimento dos jovens com a música pop é intenso, e que trazer esse tema para a escola 
de forma pedagogicamente tradicional pode ocasionar resistência por parte dos jovens. Porém, o autor destaca a importância que a música tem na formação da subjetividade e apoia um esforço mais efetivo para que a música pop seja incorporada à mídia-educação, em um ensino que acolha a lógica cultural da experiência musical cotidiana dos alunos, criando condições que favoreçam diálogos, e não interrogatórios a partir de hierarquias de gosto (Richards, 2002).

Na mesma linha, e ainda no âmbito da pesquisa britânica, Pat Brereton (2005, p. 117) afirma que "o estudo de música e seus efeitos na sociedade [...] deve se tornar uma área de crescimento para a pesquisa de mídia acadêmica no futuro". Nesta mesma perspectiva, Cremades, Lorenzo e Herrera (2013), no contexto espanhol, perceberam claras diferenças entre a música na qual o currículo oficial se baseia e os conhecimentos, gostos musicais e efeitos dos meios de comunicação que aparecem principalmente no ambiente informal de aprendizagem de adolescentes. Eles apontam a necessidade urgente de se possibilitar a entrada da música ouvida pelos estudantes no espaço escolar, para uma melhoria no processo de ensino-aprendizagem da disciplina musical, motivando os alunos a ouvir músicas desconhecidas por eles, ao mesmo tempo que escutam as músicas que lhes são mais familiares.

Quanto aos focos específicos do trabalho com a música midiática na escola, destaca-se o estudo dos videoclipes, ou vídeos musicais. McClain (2016), no contexto norte-americano, discute um conjunto de questões específicas do vídeo musical para a introdução da alfabetização midiática ${ }^{4}$ e observa que há várias tendências de pesquisas sobre esses vídeos, incluindo o exame de como eles influenciam as maneiras de pensar e se comportar do público. Da mesma forma, Ruzica-Dodig (2014) discute um projeto de criação de videoclipe que desenvolveu com meninas de uma instituição católica na Croácia, afirmando ter percebido que nesse processo ele estava em aprendizado contínuo junto com as estudantes. Para ele, a alfabetização digital nos força a estar atualizados, e só aprendemos como as mídias funcionam, experimentando-as na prática.

No contexto brasileiro, os estudos sobre mídia relacionados à educação, por sua vez, têm tido como focos principais o impacto e os desafios que a cultura digital traz à escola, as experiências inovadoras dos professores com a utilização das mídias digitais no ambiente escolar, e as dimensões políticas da relação entre mídias e educação, enquanto possibilidades de promoção de uma cidadania crítica e criativa. Em relação à música de grande circulação nas mídias, também conhecida

\footnotetext{
${ }^{4}$ Os termos mídia-educação, alfabetização midiática, alfabetização digital, educomunicação, assim como outros do mesmo campo semântico, estão sendo usados neste artigo como equivalentes, ainda que reconhecendo suas ênfases específicas e as variações de tradução.
} 
no contexto brasileiro como música popular massiva ${ }^{5}$, música midiática ou música comercial, ela tem uma presença ainda incipiente nas pesquisas educacionais, sendo contemplada apenas em alguns trabalhos, como os citados a seguir, que se referem ao consumo cultural e à emissão/recepção ou à questão de "gosto musical", e não propriamente à dimensão mídiaeducativa na formação de professores.

Uma das raras pesquisas brasileiras sobre música e mídia-educação é a de Subtil (2003), que destacou que a televisão ainda era, na época, um importante meio de consumo e fruição da música, acrescentando, porém, que a internet e as tecnologias digitais estavam assumindo a dianteira nesse processo, em especial junto aos adolescentes. A autora vê a escola como mediação que pode favorecer a produção de conhecimentos sobre a dimensão histórica e social da música na cultura midiática. Sobre a complexa questão do gosto musical, Ostetto (2003) preocupa-se com a ampliação do repertório que circula nas instituições educativas, observando que os professores devem tomar cuidado com os produtos que o mercado oferece às crianças. Ela defende a abertura de novos canais de fruição e expressão para adultos e crianças, para que não fiquem limitados ao que já conhecem.

Nesse cenário, é vital a formação de professores como ouvintes críticos, produtores, reprodutores e criadores de músicas nas licenciaturas. É o que argumenta a pesquisa de Foletto et al. (2008), ressaltando o papel de um trabalho sério e consistente sobre arte, cultura midiática, e particularmente música nesses espaços educativos. É nessa direção que o mapeamento relatado a seguir procura contribuir.

\section{O PROCESSO DE MAPEAMENTO DAS PESQUISAS}

O mapeamento de dissertações e teses que realizamos, sobre música e mídias no contexto educacional brasileiro, buscou conhecer as pesquisas acadêmicas recentes sobre o tema (2000 a 2018), para identificar o que já se sabe e as lacunas existentes no campo, principalmente em relação ao que pode contribuir para a formação de professores. O levantamento iniciou-se no Banco da Coordenação de Aperfeiçoamento de Pessoal de Nível Superior - CAPES ${ }^{6}$ e na Biblioteca Digital

\footnotetext{
${ }^{5}$ Segundo Cardoso Filho; Janotti Júnior (2006, p. 3), música popular massiva "refere-se, em geral, a um repertório compartilhado mundialmente e intimamente ligado à produção, à circulação e ao consumo das músicas conectadas à indústria fonográfica".

${ }^{6}$ Serviço da Coordenação de Aperfeiçoamento do Pessoal de Nível Superior (CAPES), acessível em http://bancodeteses.capes.gov.br. Acesso em março de 2018.
} 
Brasileira de Teses e Dissertações - BDTD ${ }^{7}$, o que significa dizer que se trata de um estudo do tipo "estado do conhecimento", porque aborda apenas um setor das publicações sobre o tema estudado (ROMANOWSKI e ENS, 2006, p. 40; ANDRÉ, 2009).

Ele foi realizado em várias etapas. Inicialmente buscamos as combinações das palavraschave: "música e tecnologias"; "música e mídias"; "educação musical e tecnologias"; "educação musical e mídias". A partir dessas combinações, mapeou-se 62 pesquisas produzidas no Brasil entre os anos de 2000 e 2018, sendo 23 teses e 40 dissertações. A segunda etapa selecionou apenas os trabalhos realizados nos cursos de Pós-Graduação em Educação, Música e/ou Comunicação e Artes, chegando assim a um total de 38 trabalhos -16 teses e 22 dissertações - sendo os seus resumos incluídos no corpus de análise. Observamos que alguns casos exigiram a leitura integral do trabalho, uma vez que os resumos nem sempre informavam as questões mais relevantes para este estudo. Em seguida, elaborou-se uma planilha no Excel para proporcionar uma visão mais ampla e minuciosa dos 38 trabalhos, identificando entre eles as semelhanças, diferenças, redundâncias e temas emergentes.

Na terceira etapa, iniciamos a análise dessa produção acadêmica, inspiradas em André (2009), procurando encontrar nos trabalhos respostas para as seguintes questões: (1) Quais os Programas de Pós-Graduação que mais desenvolvem trabalhos com o tema música e mídias?; (2) Existe algum orientador que se destaca?; (3) Quais as palavras-chave mais utilizadas nesses trabalhos, e o que revelam?; (4) Quais as metodologias mais utilizadas nesses estudos?; (5) Quais os principais sujeitos de pesquisa?; (6) Há alguma pergunta/objetivo de pesquisa mais frequente ou tema emergente?; (7) Existe alguma tendência de referencial bibliográfico?; (8) Quais as contribuições para o avanço da área?

Verificamos que em relação aos Programas de Pós-Graduação que sediaram as pesquisas, a Universidade Federal do Rio Grande do Sul (UFRGS) se destaca em primeiro lugar, com 11 trabalhos, distribuídos entre o Pós em Educação e o Pós em Música. Quatro universidades aparecem a seguir, com três trabalhos cada uma: a Universidade Federal de Minas Gerais (UFMG), a Universidade de Brasília (UnB), a Pontifícia Universidade Católica de São Paulo (PUC/SP), e a Universidade Estadual Paulista "Júlio de Mesquita" (UNESP). Em outras universidades também foram elaboradas entre uma e duas pesquisas em torno da temática nesse período, conforme a figura a seguir:

\footnotetext{
${ }^{7}$ Serviço do Instituto Brasileiro de Informação em Ciência e Tecnologia (BDTD), acessível em http://bdtd.ibict.br/vufind. Acesso em abril de 2018.
} 
Figura 1 - Teses e dissertações brasileiras sobre música e mídias por universidade (2000-2018)

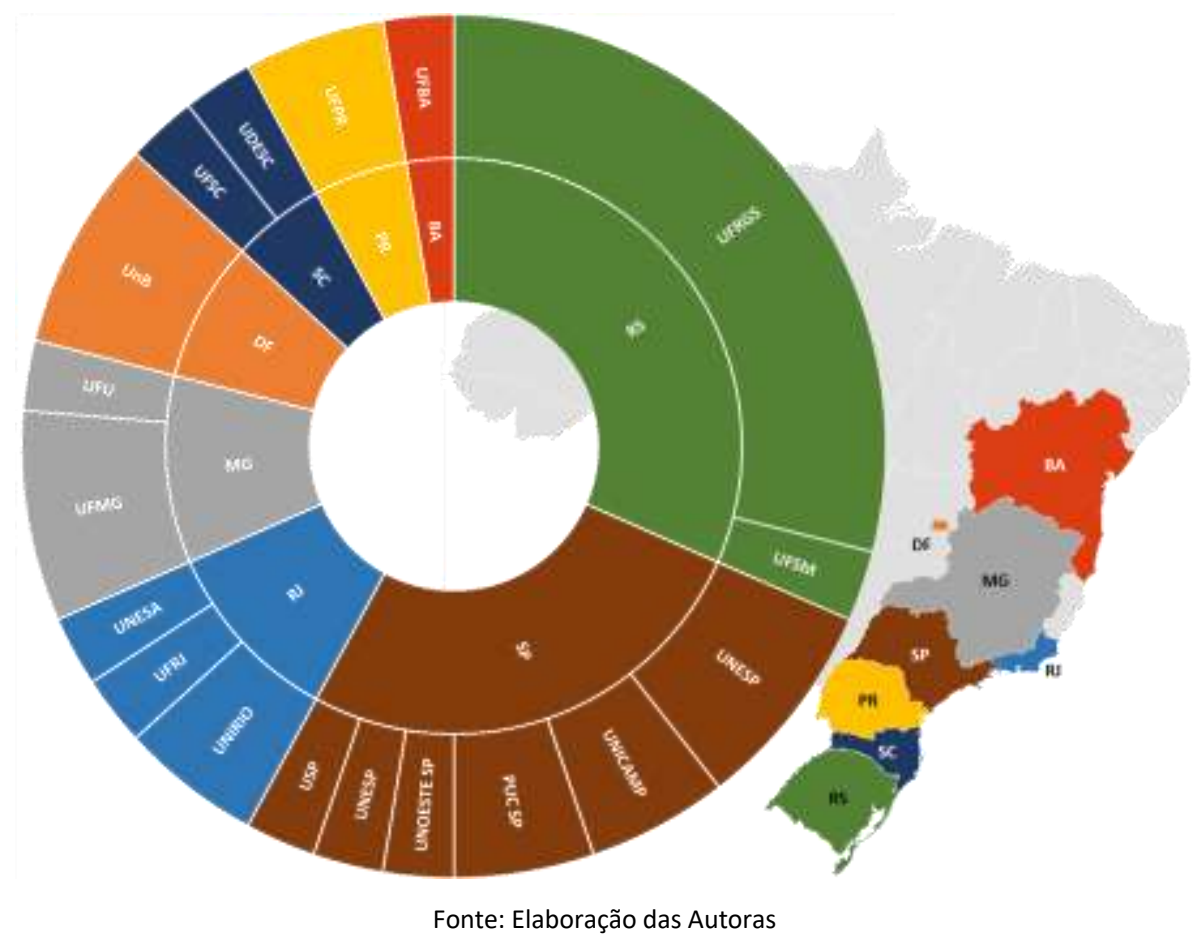

Quanto às orientações das pesquisas, destacam-se as professoras da UFRGS Jusamara Souza, que orientou quatro trabalhos (RAMOS, 2012; OLIVEIRA, 2012; LORENZI, 2007; SCHMELING, 2005), e Liane Hentschke, orientadora de três trabalhos (CERNEV, 2005; HENDERSON, 2007; RIBEIRO, 2013).Observamos que algumas das 38 pesquisas pareciam dar maior ênfase à música, outras à mídia, à formação de professores, aos cursos à distância/online ou ao uso de aplicativos no ensino musical. Para confirmar essa impressão inicial, reexaminamos todas as palavras-chave das pesquisas, além das duas que já havíamos usado como critério de inclusão. A partir daí, retiramos do corpus os trabalhos que davam ênfase aos cursos à distância ou online, e ao uso de aplicativos, por estarem fora do foco de interesse de nossa pesquisa.

Seguindo esses critérios, das 16 teses, foram eliminadas sete, ficando nove teses para análise; e das 22 dissertações, foram eliminadas 12, ficando para análise dez dissertações. Seguem abaixo (Quadro 1 e Quadro 2), assim, as referências às pesquisas que passaram constituir o corpus:

\begin{tabular}{|c|l|l|c|}
\hline Ano & \multicolumn{1}{|c|}{ Autor } & \multicolumn{1}{c|}{ Quadro 1 - Nove Teses - Música e Mídias } & \multicolumn{1}{c|}{ Tese } \\
\hline 2003 & $\begin{array}{l}\text { TORRES, Maria } \\
\text { Cecilia de Araújo } \\
\text { Rodrigues }\end{array}$ & $\begin{array}{l}\text { Identidades musicais de alunas de pedagogia: música, } \\
\text { memória e mídia }\end{array}$ & UFRGS \\
\hline 2010 & $\begin{array}{l}\text { MENDES, Adriana } \\
\text { do Nascimento } \\
\text { Araújo }\end{array}$ & $\begin{array}{l}\text { Um estudo experimental a respeito da apreciação musical de } \\
\text { alunos do ensino fundamental no ensino musical via } \\
\text { computador }\end{array}$ & UNICAMP \\
\hline 2011 & $\begin{array}{l}\text { CURTÚ, Anamaria } \\
\text { Brandi }\end{array}$ & $\begin{array}{l}\text { Música, educação e indústria cultural: o loteamento do } \\
\text { espaço sonoro no espaço escolar }\end{array}$ & UNESP \\
\hline
\end{tabular}




\begin{tabular}{|c|l|l|c|}
\hline 2012 & $\begin{array}{l}\text { RAMOS, Silvia } \\
\text { Nunes }\end{array}$ & $\begin{array}{l}\text { Escuta portátil e aprendizagem musical: um estudo com } \\
\text { jovens sobre a audição musical mediada pelos dispositivos } \\
\text { portáteis }\end{array}$ & UFRGS \\
\hline 2013 & $\begin{array}{l}\text { LIMA, Maria } \\
\text { Helena de }\end{array}$ & $\begin{array}{l}\text { Diásporas mentais e mentes diaspóricas: emergências, novas } \\
\text { tecnologias, música, educação }\end{array}$ & UFRGS \\
\hline 2013 & $\begin{array}{l}\text { SILVA, Valdirene } \\
\text { Cássia da }\end{array}$ & $\begin{array}{l}\text { E-jovens, e-músicas, e-educações: fronteiras dilatadas e } \\
\text { diálogos cruzados na era das conexões }\end{array}$ & UFBA \\
\hline 2015 & $\begin{array}{l}\text { COSTA, Gisele } \\
\text { Maria Marino }\end{array}$ & $\begin{array}{l}\text { As músicas veiculadas pelas mídias entre jovens: consumo, } \\
\text { tendências e comportamentos }\end{array}$ & UFMG \\
\hline 2016 & $\begin{array}{l}\text { PEQUINI, } \\
\text { Alexandre Trajano }\end{array}$ & $\begin{array}{l}\text { O uso das tecnologias no cotidiano, na educação e no ensino } \\
\text { musical sob uma perspectiva educacional e sociocultural }\end{array}$ & UNESP \\
\hline 2016 & $\begin{array}{l}\text { BELTRAME, } \\
\text { Juciane Araldi }\end{array}$ & $\begin{array}{l}\text { Educação Musical emergente na cultura digital e } \\
\text { participativa: uma análise das práticas de produtores } \\
\text { musicais }\end{array}$ & UNIRIO \\
\hline
\end{tabular}

Fonte: Elaboração das Autoras

Quadro 2-Dez Dissertações - Música e Mídias

\begin{tabular}{|c|c|c|c|}
\hline Ano & Autor & Dissertação & Universidade \\
\hline 2005 & $\begin{array}{l}\text { SCHMELING, } \\
\text { Agnes }\end{array}$ & $\begin{array}{l}\text { Cantar com as mídias eletrônicas: um estudo de caso com } \\
\text { jovens }\end{array}$ & UFRGS \\
\hline 2006 & LEME, Gerson Rios & $\begin{array}{l}\text { Professores de escolas de música: um estudo sobre a } \\
\text { utilização de tecnologias }\end{array}$ & UFSM \\
\hline 2010 & PEREIRA, Priscila & $\begin{array}{l}\text { A utilização de tocadores portáteis de música e sua } \\
\text { consequência para a escuta musical de adolescentes }\end{array}$ & UNESP \\
\hline 2010 & $\begin{array}{l}\text { AZOR, Gislene } \\
\text { Natera }\end{array}$ & $\begin{array}{l}\text { Música nos anos iniciais do ensino fundamental: } \\
\text { perspectivas para os trabalhos em parceria na rede municipal } \\
\text { de Florianópolis }\end{array}$ & UFSC \\
\hline 2010 & $\begin{array}{l}\text { BUENO, Paula } \\
\text { Alexandra Reis }\end{array}$ & $\begin{array}{l}\text { A educomunicação na educação musical e seu impacto na } \\
\text { cultura escolar }\end{array}$ & UFPR \\
\hline 2010 & $\begin{array}{l}\text { VALE, Fernanda } \\
\text { Feitosa do }\end{array}$ & $\begin{array}{l}\text { Juventude, mídias sonoras e cotidiano escolar: um estudo em } \\
\text { escolas de periferia }\end{array}$ & UNESP \\
\hline 2012 & POPOLIN, Álisson & $\begin{array}{l}\text { Eu gosto de escutar música todo dia [ ] Todo jovem gosta } \\
\text { Escutar música já faz parte da minha vida: Jovens, escuta } \\
\text { diária de música e aprendizagem musical }\end{array}$ & UFU \\
\hline 2013 & $\begin{array}{l}\text { REGO, Tania Maria } \\
\text { Silva }\end{array}$ & $\begin{array}{l}\text { Jovens, interações e articulações com a aprendizagem } \\
\text { musical no contexto do Ensino Médio do Instituto Federal de } \\
\text { Educação Ciência e Tecnologia do Maranhão (Campus } \\
\text { Monte Castelo) }\end{array}$ & UnB \\
\hline 2015 & $\begin{array}{l}\text { BECHARA, Silvia } \\
\text { Regina de Camera } \\
\text { Corrêa }\end{array}$ & $\begin{array}{l}\text { Jovens estudantes de música na cibercultura musical: } \\
\text { facebook e educação musical 2.0. } 2015\end{array}$ & UNESP \\
\hline 2017 & $\begin{array}{l}\text { MARTINS, } \\
\text { Mariana Roncale }\end{array}$ & $\begin{array}{l}\text { Do rec ao play e além: as gravações em uma oficina de } \\
\text { música para crianças }\end{array}$ & UDESC \\
\hline
\end{tabular}

Fonte: Elaboração das Autoras

\section{O QUE DIZEM AS 19 PESQUISAS SOBRE MÚSICA E MÍDIAS NO CONTEXTO EDUCACIONAL}

Entre os 19 trabalhos, as palavras-chave que mais aparecem são: música (10 vezes); educação musical (9 vezes); mídia e jovem (5 vezes cada); tecnologias (4 vezes); tecnologias da informação e comunicação - TIC e aprendizagem musical (3 vezes cada); ensino, escola, dispositivos (portadores) móveis e formação de professores (2 vezes cada). E todas as demais, apenas uma vez. 
Tais palavras-chave e a frequência com que aparecem nas pesquisas já nos ajudam a perceber as "novas formas de aprender e ensinar música presentes na educação musical contemporânea" (SOUZA, 2008, p. 8), como fica claro na figura abaixo:

Figura 2 - Nuvem de Palavras

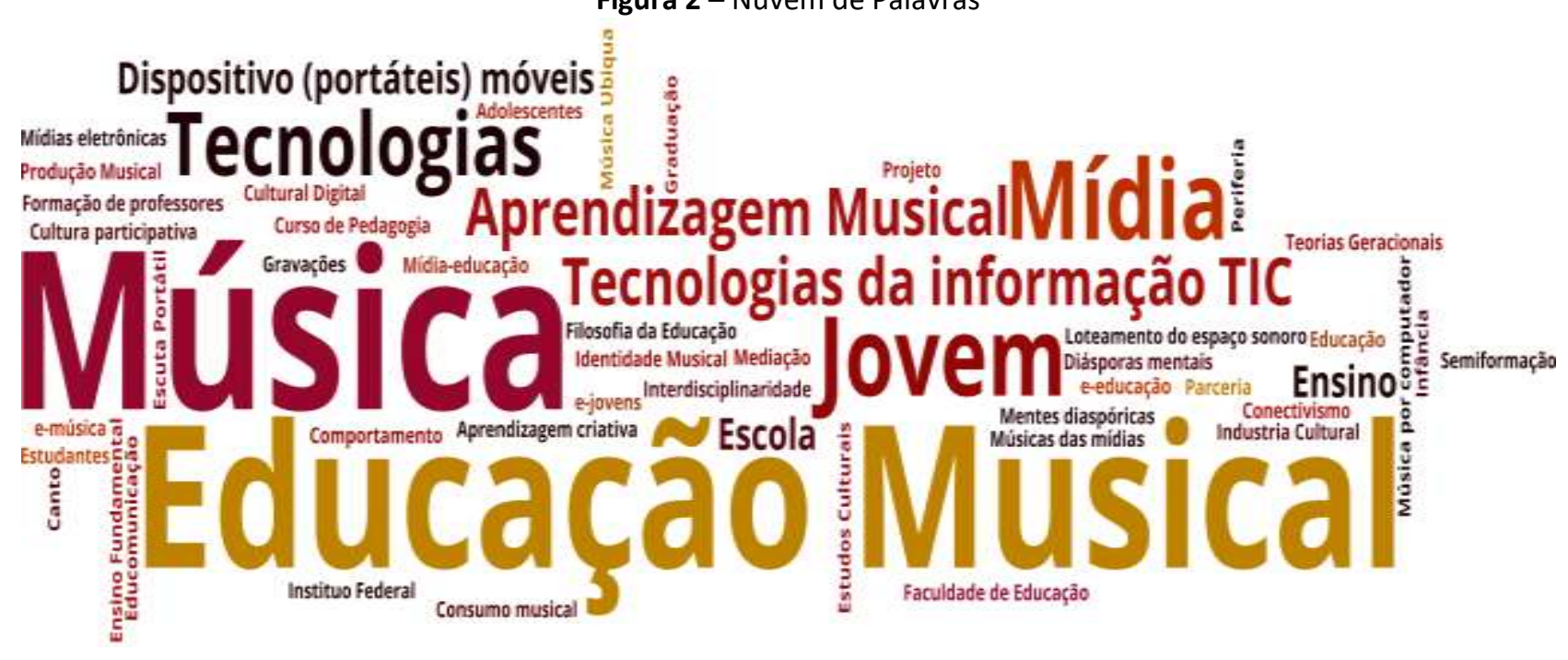

Fonte: Elaboração das Autoras

Buscando então responder às perguntas iniciais, identificamos que a metodologia mais utilizada nas pesquisas foi o estudo de caso, presente nos trabalhos de Schmeling (2005); Azor (2010) e Ramos (2012). Destacam-se também propostas inovadoras como a pesquisa qualitativa online (BELTRAME, 2016) e a "et/netnopesquisa" (SILVA, 2013). Em alguns resumos dos trabalhos selecionados, a metodologia não é explicitada, sendo apenas indicados os instrumentos de coleta de dados, como observação livre, observação do repertório musical, entrevistas semiestruturadas, grupos focais, testes de percepção musical e levantamento do acervo sonoro musical.

As perguntas e os objetivos de pesquisas são diversos, destacando-se preocupações com alguns temas emergentes: a escuta musical mediada pelos tocadores portáteis; o consumo dessas músicas e seu papel na constituição da identidade musical; e o modo como são realizadas as práticas ou produções musicais dentro dos espaços virtuais. Podemos citar como exemplo as pesquisas de Torres (2003); Schmeling (2005); Pereira (2010); Ramos (2012); Silva (2013); Costa (2015); e Beltrame (2016).

Os sujeitos de pesquisa mais investigados neste conjunto de trabalhos são os jovens (SCHMELING, 2005; PEREIRA, 2010; VALE, 2010; POPOLIN, 2012; RAMOS, 2012; SILVA, 2013; REGO, 2013), seguidos dos professores e estudantes de música (LEME, 2006; BELTRAME, 2016) e dos 
estudantes em escolas básicas públicas e/ou privadas (MENDES, 2010; CURTÚ, 2011). Destacamos, como pesquisa realizada com crianças, a dissertação de Martins (2017), que envolveu 15 estudantes entre nove e 11 anos em uma escola de música, buscando compreender como os processos de gravação se articulam nas aulas de música, dando ênfase aos sentidos que as crianças atribuem a eles. Vale lembrar ainda que há três pesquisas (AZOR, 2010; BUENO, 2010 e MARTINS, 2017) entre os trabalhos que trazem a mídia-educação e/ou a educomunicação como uma possibilidade de diálogo entre a música, a educação e as mídias.

Embora as temáticas de todos os estudos sejam música, educação, tecnologias e mídias, não percebemos uma tendência teórica mais significativa entre eles, o que demonstra abertura a diferentes perspectivas neste grupo de pesquisadores.

Encontramos nos trabalhos diversas contribuições potenciais para a formação de professores, mesmo considerando que muitas delas voltam-se especificamente à ação do educador musical. Destacamos a seguir algumas das contribuições que nos parecem mais significativas. Ramos (2012), por exemplo, que estudou o que chama de "escuta portátil", ou seja, a escuta musical por meio de dispositivos móveis, nos convida a desconstruir preconceitos em relação ao que os jovens escutam. Percebeu que a escuta portátil tem um importante papel social, e desestabiliza o conceito de apreciação individual, pois também acontece no espaço público, além de ser muitas vezes coletiva. Para os jovens, essa nova escuta musical não deve ser só armazenada, mas sim compartilhada. A escuta portátil é híbrida, e as playlists se iniciam a partir do "gosto" de cada um, do interesse por um determinado estilo musical, porém a linearidade da escuta vai sendo rompida pela variedade de estilos de interpretação e arranjos de artistas, em combinações aleatórias que desafiam a percepção, deslocando-a constantemente de uma música a outra. O estudo sugere que os professores de música promovam práticas de compartilhamento nas salas de aula, para que os jovens ampliem e construam novos conhecimentos. Sugere também que se conduza os jovens a passar de apreciadores a produtores de conhecimento musical, em uma escuta autônoma, que capacite o ouvinte a dialogar constantemente com os elementos estruturais das músicas que escuta. Na perspectiva de Ramos, pode-se escutar de tudo, desde que se aprenda alguma coisa com isso. A autora propõe uma pedagogia para o educador musical que se paute por quatro ações desenvolvidas junto aos jovens: escutar, analisar, debater e criar (RAMOS, 2012).

Em um posicionamento importante, a pesquisa de Costa (2015) avalia que os professores precisam modificar suas práticas, buscando aproximar-se daquilo que os estudantes conhecem, realizando um "aproveitamento pela escola dos hábitos de apreciação musical informal de alunos - 
para ampliação de repertório e cultura musical - procurando fazer disso um aprendizado informal de música" (COSTA, 2015, p. 152). A autora conclui que os smartphones, os tablets e os aplicativos digitais são ferramentas com grande potencial para a educação musical. E a presença das mídias digitais pode ir além de seu papel instrumental, sendo capaz de enriquecer o contexto cultural das crianças, influenciando seus modos de agir e de pensar, como aponta a pesquisa de Martins (2017).

A necessidade de mudanças no olhar do professor, para que se coloque de forma mais positiva diante da subjetividade juvenil, fica evidente também no diagnóstico de Silva (2013), que estudou as relações dos jovens contemporâneos, mediadas pela música, nos espaços virtuais, constatando que eles desenvolvem mecanismos próprios de construção de conhecimento, ancorados na liberdade, na colaboração, na autonomia e na dádiva. A autora conclui que "os ejovens, a partir de suas potencialidades avatarizadas, atuam como artífices na rede e (re)constroem o dado, desarticulando o conceito de originalidade, uma vez que, para esses sujeitos, originalidade implica pluralização do saber (SILVA, 2013, p. 137).

Também a pesquisa de Beltrame (2016) apontou a possibilidade de processos de autoaprendizagem, espaços de criação, e trabalhos em parcerias, nos quais cada um colabora com sua expertise, em uma educação musical que emerge das práticas de produção musical na cultura digital. Na mesma linha, a pesquisa de Schmeling (2005) sobre a relação dos jovens com a música, o canto e as mídias eletrônicas, destacou processos positivos no ambiente midiático-musical que eles frequentam, afirmando que "as mídias propiciam aos jovens uma aprendizagem musical na qual percebem, cantam, reproduzem e também criam, como no caso dos improvisos vocais" (p.156). A autora aponta ainda a importância de se refletir sobre o papel das escolas nesse diálogo com as mídias, pois os jovens demonstram ter uma escuta musical ampliada e não linear, e a estética musical com a qual se identificam engloba a letra da música, a orquestração, o volume sonoro, o corpo, os gestos, as coreografias, os ruídos, diferentes timbres e colocações vocais, entre outros aspectos.

A análise dos trabalhos mapeados possibilitou perceber que a função de integração entre as pessoas que a música possui vem sendo intensificada pelos novos modos de ouvir. Nesta perspectiva, Pereira (2010) propõe que a educação musical valorize a aprendizagem musical tanto na esfera escolar quanto na midiática, recomendando que as músicas ouvidas pelos estudantes em seu cotidiano fora da escola possam de alguma forma ser exploradas pelos professores para o ensino, ampliando-se também o uso das tecnologias nas aulas de música. Também valorizando as experiências musicais cotidianas, outro pesquisador, Popolin (2012) percebe que por meio da escuta 
os jovens adquirem um conjunto de conhecimentos técnicos e estruturais ligados à música. Observa que os estados emocionais influenciam a escolha da música, os usos, funções, estratégias e locais de escuta, que por fim se refletirão em variados modos de escuta. Desta maneira, o autor afirma que a educação musical deve considerar esses novos modos de escuta no contexto educacional, não para reproduzi-los na sala de aula, mas para ampliar o repertório dos estudantes (p.115).

No estudo que fez com jovens em escolas de periferia, Vale (2010) percebeu que a música que eles escutavam no cotidiano proporcionava experimentações temporais plurais, muitas vezes dissonantes da temporalidade hegemônica nos ritmos da vida social, possibilitando que as vivências musicais fossem tecidas numa cartografia de memórias afetivas. A autora encontrou toda uma diversidade de estilos musicais na sociabilidade dos adolescentes, o que problematiza o senso comum de que os jovens constituem suas habilidades em torno de um único estilo musical. A pesquisa também revela o importante papel das famílias na formação do gosto musical dos jovens, e discute a relação de conflitos entre os adolescentes e seus familiares, e as culturas musicais do rap, do funk e do rock. Essas vivências também podem ser encontradas no espaço escolar, nas relações conflituosas com os professores, sendo que a maioria destes desqualifica gêneros como o pagode, o rap e o funk. Assim, diz a autora, os professores não percebem a multiplicidade de estilos musicais presentes entre os jovens e desqualificam suas escolhas, chegando até a associá-las às classes de baixa renda. Ela problematiza ainda a "questão da corporeidade implicada no prazer da dança, que difere do controle deste corpo no ambiente escolar, onde a quietude dos gestos aparece como condição para a efetivação da aprendizagem" (VALE, 2010, p. 153). Questionando a racionalidade escolar que prima pelo uso de materiais apostilados e exercícios de perguntas e respostas prontas, a autora aponta a necessidade de desconfiarmos de "propostas pedagógicas apaziguadoras", dizendo que "é preciso antes olharmos para as diferenças, tensões e conflitos entre os jovens de periferia e a escola" (p.154), investigando as possibilidades das produções simbólicas para instaurar movimentos e criar um ambiente pautado na ética e a favor da transformação social.

Nesse contexto, não se poderia perder de vista a dimensão crítica com relação ao fenômeno que Curtú (2011) chamou de "loteamento do espaço sonoro" no âmbito da indústria cultural. Em sua pesquisa em escolas de Ensino Fundamental, a autora percebeu a ênfase das produções musicais padronizadas pela indústria cultural no acervo musical das crianças. Como vimos anteriormente, a abordagem crítica ao repertório promovido pelos interesses comerciais das indústrias midiáticas é um dos pilares tradicionais da mídia-educação, e sua importância fica aqui mais uma vez ressaltada. Considerando a complexidade da formação necessária para que os 
professores consigam dar conta de todas essas demandas e abordagens, destacamos também como valiosa a contribuição de Azor (2010), ao registrar a importância de parcerias íntimas e sistemáticas entre os professores de referência e os educadores musicais dentro da escola.

Vale registrar que neste conjunto de pesquisas encontramos algumas críticas a estudos que, ao examinarem as "relações dos jovens com a música e a possibilidade daqueles fazerem uso das TIC nesse movimento, não privilegiam seu potencial e sim o uso das tecnologias como ferramenta para alavancar o processo de educação musical" (SILVA, 2013, p. 33). Outro exemplo é a pesquisa de Pequini (2016, p.14) que afirma que "embora o uso da tecnologia esteja sendo empregado na sociedade de forma intensa, ele ainda é um tanto tímido no que se reporta aos processos de ensino e aprendizagem na educação formal e não formal".

As pesquisas citadas, enfim, ressaltam a importância de que os saberes musicais da experiência cotidiana de nossos alunos sejam compartilhados e discutidos dentro do espaço escolar. Para isso, os professores precisam estar abertos e atentos aos novos desdobramentos culturais, dispostos a facilitar e organizar escutas e práticas, tanto de músicas conhecidas quanto desconhecidas das crianças, dos jovens e deles mesmos.

\section{CONSIDERAÇÕES FINAIS}

A partir do mapeamento das 38 teses e dissertações brasileiras (2000-2018) que abordam a música e as mídias e/ou tecnologias digitais no contexto educacional, nosso trabalho se concentrou na análise de 19 pesquisas, com foco em suas contribuições para a formação de professores em relação à música e às mídias.

As investigações nos mostram a importância de se entender os movimentos da indústria cultural (PEREIRA, 2010; CURTÚ, 2011) e suas relações com os modos individuais ou coletivos que os jovens passaram a ter na sua relação com a música (RAMOS, 2012). Mais especificamente, percebemos a necessidade pedagógico-cultural de se prestar atenção à escuta musical que acontece nas experiências cotidianas, e que possibilita "a construção de conhecimentos ligados ao material sonoro de ordem estrutural e técnica" (POPOLIN, 2012, p. 89). É especialmente importante, no caso específico de produção musical, perceber que a escuta musical cotidiana perpassa os "conhecimentos sobre tonalidade, estrutura da música, ou então sobre o significado das letras" (BELTRAME, 2016, p. 148). Importante salientar também a necessidade de um entendimento 
histórico-social sobre os diferentes estilos musicais como espaço identitário e de sociabilidade entre os jovens (VALE, 2010, CURTÚ, 2011).

Várias pesquisas evidenciam o problema de que a escola ainda não se mostra preparada para receber e trabalhar com as músicas que os jovens consomem ou escutam no seu cotidiano; por outro lado, sugerem positivamente que os dados recolhidos em suas pesquisas nos ajudam a propor novas formas de abordar a música no espaço escolar. Ao mesmo tempo, e aqui apontamos uma eventual limitação desse conjunto de pesquisas, não identificamos nelas orientações objetivas sobre modos possíveis de trabalhar as músicas das mídias de forma crítica no espaço escolar.

O que as pesquisas trazem claramente são inspirações preciosas no sentido de olharmos com mais atenção para os interesses, consumos culturais, manifestações e produções realizadas por crianças, jovens e professores. Avaliamos que a maior contribuição destes estudos para o cotidiano escolar seja justamente desvelar e valorizar os outros saberes dos alunos, seus saberes de experiência, que tantas vezes são desconsiderados pela instituição escolar e pelas políticas públicas brasileiras. Corroborando essa perspectiva, que é epistemológica e também ética, observamos que diversos trabalhos não apenas fizeram ouvir as vozes dos sujeitos de pesquisa, como também as contextualizaram em cada momento sócio-político-cultural, o que consideramos de fundamental importância.

As investigações reunidas e analisadas nos animam à defesa de que os professores não fiquem limitados ao que conhecem. É preciso promover o conhecimento da música e das mídias nos espaços de formação de professores, pois é por meio dos estudos, reflexões e práticas ali vivenciados que os futuros professores poderão se tornar ouvintes críticos e criadores, e educadores abertos a novos desafios.

Defendemos a importância crucial da mídia-educação, e em particular de sua articulação com a música, para a educação dos sujeitos contemporâneos. O que se busca, em abordagens como as pedagogias críticas e os estudos culturais, não é um manual de ideias convencionais para melhorar a função de reprodução social da educação, mas um projeto que envolva os alunos, que os encoraje a desafiar ideias pré-concebidas desenvolvendo a possibilidade de uma relação com a música mais consciente, ampla e crítica, e também mais criativa.

Sabemos que o desafio de trazer a música popular midiática para dentro do espaço escolar pode provocar resistências, tanto de professores como de alunos (RICHARDS, 1995), porém as pesquisas acima indicam claramente a pertinência e o potencial pedagógico de iniciativas nessa direção. Ressaltamos ainda o quanto esse conjunto de pesquisas nos ajuda a perceber a importância 
da ampliação do repertório musical dos jovens e também de seus professores, e a valorizar as contribuições dos estudantes para processos críticos e criativos de ensino musical. Consideramos, em suma, que esse conjunto de trabalhos acadêmicos é bastante valioso, por sugerir formas de abordar a música no espaço escolar sintonizadas com as urgências contemporâneas, buscando aproximar as escolas das vivências midiático-musicais de crianças e jovens.

\section{REFERÊNCIAS}

ATALAY, Bulent. A Matemática e a Mona Lisa: a confluência da arte com a ciência. São Paulo: Mercuryo, 2007.

ANDRÉ, Marli. A produção acadêmica sobre formação de professores: um estudo comparativo das dissertações e teses defendidas nos anos 1990 e 2000. Revista Brasileira de Pesquisa sobre Formação Docente, Belo Horizonte, v. 01, n. 01, p. 41-56, ago/dez. 2009.

BELLOCHIO, Claudia. Formação musical de professores na pedagogia: pressupostos e projetos em realização na UFSM/RS. In: Encontro Anual da Associação Brasileira de Educação Musical, 13, 2004, Rio de Janeiro. Anais... Rio de Janeiro: ABEM, 2004. p. 208-216.

BELLOCHIO, Claudia Ribeiro; WEBER, Vanessa; SOUZA, Zelmielen Adornes de. Música e Unidocência: pensando a formação e as práticas de professores de referência. In: Revista da FAEEBA - Educação e Contemporaneidade, Salvador, v. 26, n. 48, p. 205-221, jan./abr. 2017.

BELLOCHIO, Cláudia Ribeiro; SOUZA, Zelmielen Adorne de Souza. Professor de referência e unidocência: pensando modos de ser na docência dos anos iniciais do ensino fundamental. In: BELLOCHIO, Cláudia Ribeiro (Org.). Educação musical e unidocência: pesquisas, narrativas e modos de ser do professor de referência. Porto Alegre: Sulina, 2017. p. 13-35.

BRASIL. Ministério da Educação e Cultura. Lei de Diretrizes e Bases da Educação Nacional (LDB). Lei 9394/96. Brasília, 1996. Diário Oficial da União, Ano CXXXIV, n. 248, de 23/12/96, p. 27.833 -

27.841 (publicação original), 1996. Disponível em: http://www.planalto.gov.br/ccivil_03/Leis/L9394.htm

BRASIL. Ministério da Educação. Resolução CNE/CP no 1, de 15 de maio de 2006. Institui Diretrizes Curriculares Nacionais para o Curso de Graduação em Pedagogia, licenciatura. Brasília, DF, 2006. Disponível em: http://portal.mec.gov.br/cne/arquivos/pdf/rcp01_06.pdf. Acesso em: 20 jun. 2019.

BRASIL. Presidência da República. Lei no 11.769, de 18 de agosto de 2008. Altera a Lei n. 9.394/96, para dispor sobre a obrigatoriedade do ensino de música na educação básica. Brasília, DF, 2008. Disponível em: http://www.planalto.gov.br/ccivil_03/_Ato2007-2010/2008/Lei/L11769.htm. Acesso em: 20 jun. 2019.

BRASIL. Presidência da República. Lei no 13.278, de 2 de maio de 2016. Altera o § 60 do art. 26 da lei no 9.394, de 20 de dezembro de 1996, que fixa as diretrizes e bases da educação nacional, referente ao ensino da arte. Brasília, DF, 2016. Disponível em: 
http://www.planalto.gov.br/ccivil_03/_Ato2015-2018/2016/Lei/L13278.htm. Acesso em: 20 jun. 2019.

BRERETON, Pat. The continuum guide to Media Education. Bloomsbury Publishing, 14 de set de 2005.

BUCKINGHAM, David. Going Critical: on the problems and the necessity of media criticism, 2018. Disponível em: https://ddbuckingham.files.wordpress.com/2018/07/going-critical.pdf Acesso em 10 de maio de 2019.

CARDOSO FILHO, Jorge; JANOTTI JÚNIOR, Jeder. A música popular massiva, o mainstream e o underground- trajetórias e caminhos da música na cultura midiática. Intercom- Sociedade Brasileira de Estudos Interdisciplinares da Comunicação. XXIX Congresso Brasileiro de Ciências da Comunicação. UnB, 06 a 9 de dezembro de 2006.

CATTERALL, James; DUMAIS, Susan Alexandra; HAMPDEN-HOMPSON, Gillian. The arts and achievement in at-risk youth: findings from four longitudinal studies. National Endowment for the Arts, 2012. Disponível em: https://www.arts.gov/sites/default/files/Arts-At-Risk-Youth.pdf. Acesso em 06 de março de 2019.

CORREA, Aruna Noal. "Programa LEM: tocar e cantar": um estudo acerca de sua inserção no processo músico-formativo de unidocentes da Pedagogia/UFSM. 2008. 175 f. Dissertação (Mestrado em Educação) - Universidade Federal de Santa Maria (UFSM), Santa Maria, RS, 2008.

CREMADES, Roberto; LORENZO, Oswaldo, HERRERA, Lucía. Estilo musical y curriculum en la Enseñanza Secundaria Obligatoria. E-book v. 1.0 Editorial Club Universitario. San Vicente (Alicante), 2013.

FIGUEIREDO, Sergio Luiz Ferreira. A música e as artes na formação do pedagogo: polivalência ou interdisciplinaridade? Revista da FAEEBA - Educação e Contemporaneidade, v.26, p.79 - 96, 2017.

FOLETTO, Denize da Silveira; SILVA, Valmir da; CARVALHO, Elvio de; BOHRER, Jacimira Hoher; TREVISAN, Amarildo Luiz. Emissão e recepção midiática musical no contexto escolar: um desafio pedagógico para o professor. Anais... XVIII Congresso da Associação Nacional de Pesquisa e PósGraduação (ANPPOM), Salvador - 2008.

JENKINS, Henry, PURUSHOTMA, Ravi; WEIGEL, Margaret; CLINTON, Katie; ROBISON, Alice. Confronting the Challenges of Participatory Culture: media education for the 21st century. Cambridge: MIT/ MacArthur Foundation, 2009. Disponível em https://www.macfound.org/media/article_pdfs/JENKINS_WHITE_PAPER.PDF. Acesso em 07 de agosto de 2019.

KELLNER, Douglas, SHARE, Jeff. Educação para a leitura crítica da mídia, democracia radical e a reconstrução da educação. Trad. de Márcia Barroso, com revisão de Antonio Zuin. Educa. Soc., Campinas, vol. 29, n. 104- Especial, p. 697-715, out. 2008. Disponível em:

https://www.scielo.br/pdf/es/v29n104/a0429104.pdf Acesso em 07 de agosto de 2019.

MCCLAIN, Jordan. A Framework for using popular music videos to Teach Media Literacy. Dialogue: 
The Interdisciplinary Journal of Popular Culture and Pedagogy. 3 (1) Disponível em:

http://journaldialogue.org/issues/a-framework-for-using-popular-music-videos-to-teach-medialiteracy/_Acesso em 10 de maio de 2019.

NEW YORK CITY. Blueprint for Teaching and Learning in the Arts: Music. Department of Education, 2015.

OSTETTO, Luciana Esmeralda. "Mas as crianças gostam" ou sobre gostos e repertórios musicais. Anais... 26a Reunião Anual da ANPEd, Poços de Caldas, 2003. 18 p. Disponível em: <http://26reuniao.anped.org.br/>. Acesso em: 05 out. 2003.

PALHEIROS, Graça Boal. Funções e modos de ouvir música de crianças e adolescentes, em diferentes contextos. In: Em busca da mente musical: ensaios sobre os processos cognitivos em música- da percepção à produção. Beatriz Senoi llari. (organizadora). Colaboradores Beatriz Raposo de Medeiros ... [et al.]. Curitiba: Ed. da UFPR, 2006.

PENNA, Maura. A Lei 11.769/2008 e a Música na Educação Básica: quadro histórico, perspectivas e desafios. InterMeio: revista do Programa de Pós-Graduação em Educação, Campo Grande, MS, v.19, n.37, p.53-75, jan./jun. 2013.

RICHARDS, Chris. The English Curriculum - What's music got to do with it?, Changing English: Studies in Culture and Education, 1:2, p. 66-82, 1994.

RICHARDS, Chris. Popular Music Media Education, Discourse: Studies in the Cultural Politics of Education, 16:3, p. 317-330,1995.

RICHARDS, Chris. Teen Spirits: Music and Identity in Media Education. E-Library Taylor \& Francis, 2002.

ROMANOWSKI, Joana Paulin; ENS, Romilda Teodora. As pesquisas denominadas do tipo "estado da arte" em Educação. Diálogo Educ., Curitiba, n. 19, p. 37-50, set./dez. 2006.

RUZICA-DODIG, Laurea. Music Video in Education and Promotion. In: Accademia di Belle Arti di Brescia Santa Giulia. Dipartimento di Arti Visive Scuola di Grafica, 2013-2014.

SCHWAN, Ivan Carlos; BELLOCHIO, Cláudia Ribeiro; AHMAD, Laila Azize Souto. Pedagogia e Música: um mapeamento nos anais dos Encontros Nacionais da Associação Brasileira de Educação Musical e nas revistas da ABEM entre 2008 e 2017. Revista da Abem, v. 26, n. 41, p. 115-138, jul./dez. 2018.

SODRÉ, Muniz. Reinventando a educação: diversidade, descolonização e redes. / Muniz Sodré. - 2 Ed. Petrópolis, RJ: Vozes, 2012.

SOUZA, Jusamara. Aprender e ensinar música no cotidiano. Org. por Jusamara Souza. Porto Alegre: Sulina, 2008. (Coleção Músicas). 
SUBTIL, Maria José Dozza. Músicas, mídias e escola: relações e contradições evidenciadas por crianças e adolescentes. Educar em Revista, Editora UFPR, Curitiba-PR, n. 40, p.177-194, abr/jun, 2011.

VALLIENGO, Camila. Tocando e cantando... desenvolvendo a linguagem musical na rede municipal de ensino. In: Encontro Anual da Associação Brasileira de Educação Musical, 16, 2007, Campo Grande (MS). Anais... Campo Grande: Ed. da UFMS, 2007, p.01-04.

\section{SOBRE AS AUTORAS}

\section{Gislene Natera}

Doutoranda no Programa de Pós-Graduação em Educação, Universidade Federal de Santa CatarinaUFSC, Florianópolis/SC, Brasil. Grupo de Pesquisa: Núcleo Infância, Comunicação, Cultura e Arte. E-mail: gislenenatera@gmail.com

ORCID: http://orcid.org/0000-0002-9769-5501

\section{Gilka Girardello}

Doutora em Ciências da Comunicação (USP); professora Titular da Universidade Federal de Santa Catarina; Programa de Pós-Graduação em Educação da UFSC; Coordenadora do Núcleo Infância, Comunicação, Cultura e Arte.

E-mail gilkagirardello@gmail.com

ORCID: https://orcid.org/0000-0002-5316-0038 